\title{
Professional competencies in engineering education: the PREFERed-way
}

Professional competencies vary across engineering job characteristics. The design of the educational environment should take into account this diversity and enable students to develop career awareness. The European project PREFER (Professional Roles and Employability for Future EngineeRs) has developed instruments to make engineering students aware of the existence of professional roles and their associated competency profiles. These are designed and validated in strong interaction with industry, guaranteeing a discipline-independent, future-proof framework that is ready to implement in the engineering curriculum. In this paper, we describe the integration of this framework in the Faculty of Engineering Technology of KU Leuven, Belgium. The selection of professional competencies based on professional roles, the adaptive level of the professional competencies thanks to electives and the collaborative assessment of the students by experts in professional competencies and experts in technological competencies, are key elements of the new engineering curriculum. All of them are developed thanks to a university-business collaboration. The reformed curriculum will start from the academic year 2020-2021.

Keywords: competency, career awareness, curriculum development, professional role, engineering education, university-business interaction

\section{Acknowledgement}

This work was supported by Erasmus+ programme of the European Union (grant agreement 575778-EPP-1-2016-1-BE-EPPKA2-KA) and is part of the PREFER project (Professional Roles and Employability for Future Engineers, www.preferproject.eu).

\section{Author Information}

Greet Langie, KU Leuven, Faculty of Engineering Technology, Leuven Engineering and Science Education Center (LESEC). https://orcid.org/0000-0002-9061-6727

Sofie Craps, KU Leuven, Faculty of Engineering Technology, Leuven Engineering and Science Education Center (LESEC). https://orcid.org/0000-0003-2790-2218

How to cite this article:

Langie, Greet, Sofie Craps. "Professional competencies in engineering education:

the PREFERed-way.” Információs Társadalom XX, no. 2 (2020): 142-153.

$=$ https://dx.doi.org/10.22503/inftars.XX.2020.2.10

All materials

published in this journal are licenced

as CC-by-nc-nd 4.0 


\section{Introduction and literature review}

Engineers are key players in the conversion of research into innovative market applications. The UNESCO sustainable Development goals (UNESCO 2015) force engineers to apply new sustainable models for design, production and marketing of high value-added, innovative products, systems and services. This results in a more strongly emphasized and highlighted reflection on the future of engineering education and the future of the engineering profession.

Many studies have been published about this foresight exercise: The engineer of 2020: visions of engineering in the new century (NAE 2004), Education Engineers for the 21st Century (Royal Academy of Engineering 2007), Thinking like an engineer (Royal Academy of Engineering 2014), The role of engineers in the reindustrialization of Europe (EESC 2015), Engineering skills for the future (Royal Academy of Engineering 2019), etc.

These publications report very similar challenges for engineering education: interdisciplinary and system-based approaches; support for integrating new teaching technologies into the engineering classroom and for preparing engineers for new technologies; demands for an increasingly diverse talent pool of engineers; addressing the lack of hands-on/application experiences for undergraduates; a re-focus on the design side of engineering; an emphasis on the business side of engineering; increasing industry involvement in the education; turning more attention to the preparedness for the workforce; organizing Continuous Professional Development (CPD) and preparing students in general for teamwork and professional communication. In the context of these discussions, one can read very often the suggestion to embrace research in engineering education in order to support curriculum and educational materials development based on evidence-based methodologies (NAE 2004; Borrego 2011).

Several researchers have published papers focusing more deeply on specific topics. For example, the role and specificity of new teaching methodologies is described by Edström and Kolmos (2014). Ford and Riley (2003) focus on the benefits of integrating communication in engineering education. Moreover, Kegan \& Lahey (2009) call for new skills such as loyalty, team player, and self-direction in addition to technical and communication competencies. They call it 'self-authorship'. Several authors stress the importance of integrating these professional competencies in engineering challenges, in order to make the tasks authentic (Male 2010; Male, Bush and Chapman 2011; Liebenberg and Mathews 2012; Idrus 2014). These real-world challenges are easier achievable when industry is more involved in engineering education. Since companies play a crucial role in shaping the image of the engineering profession, this might also improve the career management skills of engineering students. When students meet the workspace during their education they also become more aware of the role models, exemplifying the many positions open to technical graduates. 
The conclusion is clear: engineers need more than only technical expertise. Technological knowledge is critical, but also the 'broader' competencies are essential for the 21st century organizations. Then one can ask, "Which competencies should be added?" Many studies have been done related to this question: in Australia the DeSeCo framework has been developed based on 300 completed 64-items surveys by established engineers (Male et al 2011), in the UK the Engineering Council sets the overall requirements for the Accreditation of Higher Education Programmes (AHEP 2014). The EUR-ACE Framework is an European Network for Accreditation of Engineering Education (2008) and ABET is the US-counterpart accrediting programmes in applied and natural science, computing, engineering and engineering technology. All of them include non-technological or professional competencies, such as communication, teamwork and lifelong learning.

Integrating the training and the assessment of professional competencies into the curriculum requires time. The options to handle this extra assignment are, according to the National Academy of Engineering (2004, p. 41): “(a) Cutting out some of the current requirements, (b) restructuring current courses to teach them much more efficiently, or (c) increasing the time spent in school to become an engineering professional."

The latter is often impossible because of the financial consequences. So most of the time (a) and (b) need to be combined to some extent.

Fortunately, engineers do not have to shine in all professional competencies. Research reveals that the importance of professional competencies vary across job characteristics (Nilsson 2010; Male et al. 2011; Royal Academy of Engineering 2007). This is exactly what the PREFER project has been focusing on.

\section{Objectives of the PREFER project}

The European project PREFER (Professional Roles and Employability of Future Engineers) aims to reduce the skills mismatch in the field of engineering by raising awareness of the future self. In order to realize this aim, a well-balanced consortium was built with universities (University of Leuven [Belgium], Delft University of Technology [The Netherlands] and Technical University of Dublin [Ireland]), companies (Engie, Siemens and ESB) and an experienced test development partner (BDO). To establish a stable connection with the engineering labour market, the three national engineering federations in Belgium, The Netherlands and Ireland were brought on board (IE-net, KIVI, Engineers Ireland), as well as Belgium's largest employers' organisation and trade association (Agoria). These federations and associations play an essential role in connecting higher education institutions with a large number of employers that hire engineers. Validation in a wider European network of universities and companies will be tackled by respectively SEFI and FEANI. 
As mentioned in the previous section, professional competencies vary across job characteristics. In this paper, we will focus on how education can harness and benefit from this diversity of roles in the field of work. Our conclusion will be based on the outcomes of the following three research questions:

(1) How can we describe the different roles an engineer can take on at the beginning of the career, independently of the engineering discipline (e.g. electrical, mechanical, chemical, etc.)? Can we develop a Professional Roles Framework for Future Engineers?

(2) What are the professional competencies characterizing each role? Can we confirm that the professional competencies vary across job characteristics?

(3) How can we include them in the curriculum in an integrated way, minimizing the loss of current requirements? How can we make flexible programmes, considering the job diversity?

To formulate answers to these research questions there was an intensive interaction between the project partners (universities, companies and engineering societies) and extra volunteering companies interested in the project. This was a rich source for innovation in education. In the following sections, we will first describe how industry was involved in the different stages as well as the methodologies. Second, the main outcomes addressing the three research questions are presented followed by the discussion.

\section{University-industry interaction: the magic word}

The interaction with industry started already before the start of the PREFER project. In 2015, we analysed 7672 vacancies, organised 5 semi-structured interviews with HR managers and analysed 121 surveys completed by company representatives on job fairs (Hofland et. al. 2015). We aimed to verify the validity of some possible models and the substantial presence of professional roles in the professional life. The Treacy and Wiersema model (1993) was put forward as a promising framework to look at the variety of engineering positions.

\subsection{Professional Roles Framework for Future Engineers}

In 2018, we conducted a systematic literature review and found a high degree of convergence between the framework suggested by Hofland et al (2015) and those of Kamp \& Klaassen (2016) and Spinks, Silburn \& Birhall (2007). This allowed us to develop the PREFER model. However, in an attempt to identify distinguishing competencies, we were hindered by the inconsistency of methods and a lack of well-defined competencies (Craps et. al. 2020). So we returned to industry in order to obtain an overview of the essential competencies for each of the professional roles. 


\subsection{Competencies defining the professional roles}

First, we distributed a paper and pencil survey during the job fairs at six different university campuses in the spring of 2018. In total, 188 completed surveys were retrieved in which we measured company representatives' perceptions of the selected Professional Roles Model through descriptive questions. In the second part of the survey, company representatives were requested to evaluate the importance of 15 professional competencies for each of the three professional roles (Craps, Pinxten and Langie 2019). The findings indicated that business/industry professionals hold different expectations towards the three professional roles in terms of the required professional competencies. However, using Likert-type scales, the respondents might have been driven by a propensity to provide the maximum score for each of the competencies. This propensity could stem from a desire for versatile engineers who excel in a wide variety of skills domains. A mixed method approach would allow us to refine our understanding of which competencies are quintessential for each of the three professional roles.

Therefore, we identified 12 different companies from different sectors and asked them to select 6 to 8 engineers and 1 or 2 HR managers or recruiters with expertise in hiring engineers. At each company, we set up an expert panel discussion based on the Delphi methodology (Craps et. al. 2018). A 13th mixed meta panel was organized with experts from different sectors and from companies with different sizes (start-up, SME (small and medium-sized enterprises), large company, independent entrepreneur) in order to consolidate the results of the 12 other panels.

\subsection{Professional roles in the engineering curriculum}

The industry's view on the curriculum in general is collected through our Faculty Senate and through an extensive survey in 2015 answered by 1948 alumni and 534 companies (KU Leuven 2015). In 2015, technological knowledge seemed to be the most important competency for engineers according to the companies, followed by problem solving, project-based work, managing complexity, teamwork, etc. This sequence remained the same when we asked them how the relevance of these competencies would evolve in the near future, only managing complexity and project-based work interchange. $85 \%$ of the participating companies and $89 \%$ of the responding alumni is in favour of a compulsory company internship in the curriculum. $44 \%$ of the alumni indicated that they would have been better prepared for professional life if there had been specific electives in the study programme. Also in 2015, the Faculty Senate initiated the idea of working with different professional roles. During the following meetings, they confirmed the need for integrating professional competencies in regular activities such as laboratories, projects, workshops, 
etc. They advised to organize interdisciplinary teamwork, extracurricular activities, international internships, lifelong learning stimuli, study relevant student jobs, and last but not least more collaboration between industry and academia in education (company visits, guest lecturers, internships, sabbaticals in companies, etc.). Since 2018-2019 KU Leuven has been preparing a huge reform of the programmes in Engineering Technology. Educational staff, as well as students and industry have been involved intensively in this process. The new programme will be implemented in 2020-2021 starting with the first year of the Bachelor's programme, in which every year more than 1200 new students enrol.

\section{Results}

As stated by Hofland et al. (2015), there is a wide variety in career paths for graduated engineers. Going beyond the typical specialist versus management-dichotomy, this diversity is reflected both in terms of disciplinary wealth (e.g. electrical engineering, chemical engineering, civil engineering ...) and the professional roles that engineers fulfil in a particular organization (e.g. service engineer, technical sales engineer, product engineer, process engineer ...). An important challenge of the PREFER project is to come up with an integrative framework wherein this multitude of engineering positions is summarized in a manageable and sensible way. However, it is not our intention to put forward a perfect classification model wherein each engineering position holds a unique place that is mutually exclusive. Instead, we argue in favour of a flexible framework wherein engineering positions can be described in overlapping sections if they fit several professional roles.

\subsection{Professional Roles Framework for Future Engineers}

Based on the analyses of 2015 and 2018, it turned out to be possible to make a categorization of three different professional roles: (1) an engineer that organizes and optimizes processes with a focus on efficiency; (2) an engineer that develops new leading-edge products or technologies with a focus on industrial innovation and (3) an engineer that provides solutions according to the needs of the customer with a focus on customer satisfaction (see Figure 1). Based on the business strategy model of Treacy and Wiersema (1993), we called them: (1) operational excellence, (2) product leadership and (3) customer intimacy (Hofland et al. 2015). The extensive survey distributed in 2018 revealed that $65 \%$ of the respondents (easily) recognizes the model for classifying engineering graduates in their respective company and over $60 \%$ of the respondents indicated that they could (very) easily apply the model in their respective companies (Craps et al. 2019). 


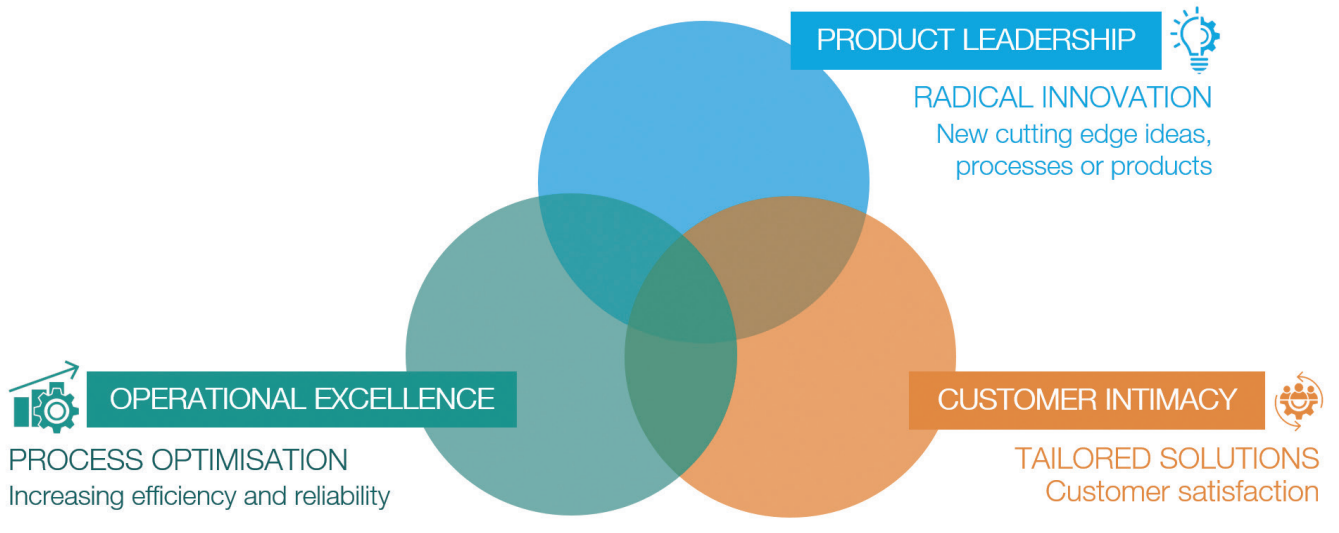

Figure 1. Professional Roles Model for Future Engineers

\subsection{Competencies defining the professional roles}

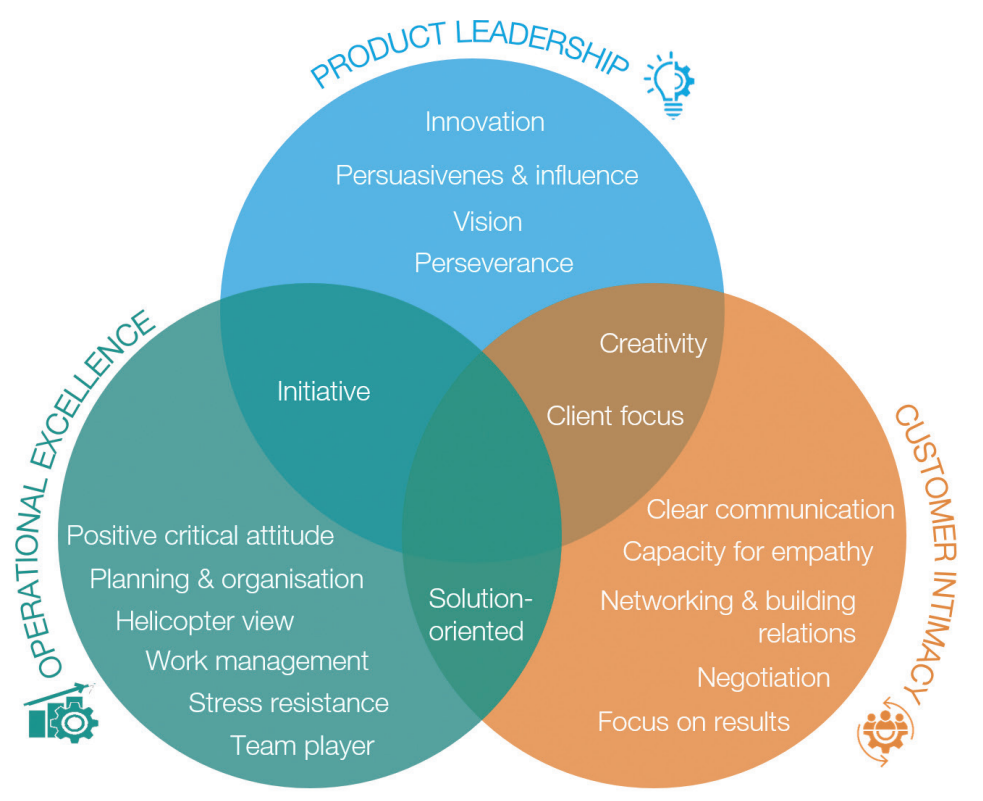

Figure 2. Competency profiles of the PREFER Professional Roles Model

The expert panels organised in 2018 identified 7 to 8 key competencies for each professional role (see Figure 2). Some of them are shared between two roles, but then their meaning might be role specific. For example 'client focus' in a product leadership role means knowledge of the market needs in order to discover gaps which can be filled with new products and processes, whereas in a customer intimacy role the focus is on partnership with the client in order to de- 
velop products and processes custom-made for the customer (Craps et al. 2018). A comprehensive overview of the competency mapping process and definitions of the identified professional competencies is subject of a paper in progress.

\subsection{Integrating professional roles in the engineering curriculum}

One of the key goals of the new KU Leuven engineering programme is 'improving critical reflection about the individual educational paths by increasing career awareness'. Based on literature and the advices of industry and alumni, we will integrate the reflection, the training and the evaluation of the professional competencies into discipline-specific courses. For example, in the first-year Bachelor's Programme 9 of the 60 ECTS points are dedicated to 'engineering experiences', in which students have to operate as an engineer. The integration of information skills, professional communication, project management, teamwork and safety is the essence of this course. First of all the theoretical framework of these professional competencies will be explained during seminaries (1 ECTS point). Afterwards students will apply and train them while performing authentic tasks. Experts and coaches will give feedback during the process and close up the trajectory with a summative assessment at the end. The professional roles will be introduced into the curriculum in a gradual way:

\subsubsection{Introduction}

In the first year we would like to make students aware of the fact that industry needs different types of engineers. Students will have to job shadow a professional during a day, reflect on the tasks and competencies they have observed and discuss this with their colleagues who have followed other engineers.

\subsubsection{Awareness of the different professional roles}

During the company visits and the guest lectures in the second year, students will have to assign the appropriate professional roles to the viewed professionals in action.

\subsubsection{Reflection on the possible personal professional role(s)}

Thanks to the two developed tests within the PREFER project, PREFER explore (Carthy et. al. 2019) and PREFER match, students can align to a range of professional roles based on their interests, attitudes and competencies. The PREFER explore test is a short personal preference test allowing students to explore the different roles and reflect on their professional preferences early in education. The PREFER match tests - one for each role - are a more elab- 
orated, engineer tailored, situational judgement tests. These tests, requiring some engineering (educational) experiences and therefor suggested to take in a later stage of the education, give insight in the alignment with the different roles including feedback on the personal role outcome and the judgment of the competencies compared to experts in the field.

\subsubsection{Specific skills training}

In the Master's programme we intend to label the Master's theses based on the three professional roles and we will include electives that students can select based on the professional role(s) in which they would like to become an expert. Since these electives will be based on the competency profiles of the three defined professional roles, students should have the necessary career awareness and professional competencies when entering the labour market. Important to notice is that it's our goal that each student obtains a minimum level for a set of key professional competencies, independent of the selected professional role. This set of key professional competencies is the same for all students, independent of their discipline, and is selected in close collaboration with industry. The electives will give them the opportunity to become an expert in some specific professional competencies associated to the selected profession role.

\section{Discussion}

This project started with a clever remark of one of the Faculty Senate members: "The most difficult question one can ask a freshly graduated engineer during a job interview is: What are your strengths and weaknesses? Students seem not to be aware of the professional role they might fit in."

An extensive literature review made by Craps et al. (2020) showed a huge diversity of possible professional roles frameworks, depending on the goals and the context. Since the PREFER project was in need of a flexible and validated professional roles framework that focuses on young engineers (max 3 years after graduation), transcending the disciplines, we further developed the model suggested by Hofland et al. (2015) as it showed high similarities with the model of Spinks et al. (2007). These models seemed promising as both researchers stressed the flexibility of their frameworks allowing to operate in two or more roles or to change roles in the career. This flexibility was strongly recognized by industry (Craps et al. 2019). Students also found the three roles easy to recognize and a valuable instrument to reflect on their professional future (Craps et. al. 2019). It might be interesting to discuss the similarities between the two models.

When one wants to define competency profiles associated with professional roles, one should start from a comprehensive overview of competencies 
that are important for success in engineering. Carthy et al. (2018) reviewed papers published in this area that used Likert scale data and had to conclude even so that due to the wide variation in the lists of competencies used in these studies, little agreement was found on what competencies were most important for success in the labour market. No one doubts that the technological knowledge is the most important competence for engineers. However, we are missing a classification and typology for the competencies not specifically related to a particular job or academic discipline, let alone we can name them. Several names can be found in literature: soft skills, professional competencies, employability skills, non-technical competencies, transversal skills, transferable skills, 21st century skills, etc. We cannot compare different frameworks found in literature. In contradiction to the US (ABET 2019), Europe has no discipline-independent obligatory set of engineering student outcomes. We look forward to the ESCO classification (European Classification of Skills/Competencies, Qualifications and Occupations) that is in its final stage for the moment (https://ec.europa.eu/esco/portal/home). We used a well-defined list of 64 professional competencies as our starting point, leaving room for adding missing competencies. This list is made by BDO, Human Capital, our partner in the project, and it was the outcome of both research (Bartram 2005) and BDO experience. We are aware that this approach has also its limitations and should be interpreted within these boundaries. Our discipline-wide curriculum reform is based on many interactions with our stakeholders and a literature study. The study of Graham (MIT 2018) for example and the integrated engineering programme of UCL (Mitchell, Nyamapfene, Roach and Tilley 2019) have inspired us intensively. The spine of Problem Based Learning at UCL is taken over, but we go one step further in the integration: the experts in the professional competencies will collaborate in the projects with the domain-specific experts and assess the students both informal and formal during the process. The impact and the student perceptions of this interdisciplinary coaching will be the subject of future publications. The next step to take is the provision of mentors from industry into these projects.

\section{Conclusion}

The importance of professional competencies for engineers is no point of discussion. However the weight associated to each competency and the way they should be integrated into the curriculum is university-, discipline- and professional role-specific. We have described how the PREFER project has developed different methodologies to look at it and how KU Leuven will integrate this in the curriculum at the Faculty of Engineering Technology. This can be a potential resource for other engineering institutions when addressing the challenge in preparing the engineers of the future. 


\section{References}

ABET. Retrieved from https://www.abet.org/accreditation/accreditation-criteria/criteria-for-accrediting-engineering-programs-2020-2021/ Accessed January 5, 2019.

Bartram, D. "The great eight competencies: A criterion-centric approach to validation.” Journal of Applied Psychology 90, no. 6 (2005): 1185-1203. https://doi.org/10.1037/0021-9010.90.6.1185.

Carthy, D., M. Pinxten, K. Gaughan, B. Bowe. “Undergraduate Engineers’ Preference for a Range of Professional Roles.” Journal of Sustainable Design \& Applied Research 7, no. 1 (2019). https://arrow.tudublin.ie/sdar/vol7/iss1/6.

Carthy, D., K. Gaughan, B. Bow. "What are the engineering professional competencies?” In: Proceedings of the 46th SEFI Annual Conference 2018. Presented at the 46th SEFI Annual Conference: Creativity, Innovation and Entrepreneurship for Engineering Education Excellence, Copenhagen, Denmark, 17 Sep 2018-21 Sep 2018. Brussels. ISBN: 978-2-87352-016-8.

Craps, S., M. Pinxten, G. Saunders, M. Leandro Cruz, K. Gaughan, G. Langie.. "Professional Roles and Employability of Future Engineers.” (499-507). Presented at the SEFi Conference, Azores Portugal, 18 Sep 2017-21 Sep 2017. European Society for Engineering Education SEFI. ISBN: 978-989-98875-7-2.

Craps, S., M. Pinxten, H. Knipprath, G. Langie. "Wanted: super(wo)man A study to define professional roles for future engineers by distinctive professional competences.” In: Proceedings of the 46th SEFI Annual Conference 2018, (148-157). Presented at the 46th SEFI Annual Conference: Creativity, Innovation and Entrepreneurship for Engineering Education Excellence, Copenhagen, Denmark, 17 Sep 2018-21 Sep 2018. Brussels. ISBN: 978-2-87352-016-8.

Craps, S., A. van de Kerkhof, M. Pinxten, H. Knipprath, G. Langie,. "Preparing Engineers for the Future by Raising Awareness of Professional Roles.” In: Academic Proceedings of the 2019 University-Industry Interaction Conference Series, (188-202). Presented at the University-Industry Interaction Conference, Helsinki, Finland, 18 Jun 2019-20 Jun 2019. ISBN: 9789-491-901-409.

Craps, S., M. Pinxten, G. Langie. "Industry Validation of a Professional Roles Model to Promote Engineering Identity of Young Graduates.” In: SEFI 47th Annual Conference Proceedings 2019, (1519-1530). Presented at the SEFI 47th Annual Conference: Varietas delectat... Complexity is the new normality, Budapest, Hungary, 16 Sep 2019-20 Sep 2019. Brussels. ISBN: 978-2-87352-018-2.

Craps, S., M. Pinxten, Knipprath, H., and Langie, G.. "Exploring professional roles for early career engineers: a systematic literature review.” European Journal of Engineering Education, (2020) DOI: https://doi.org/10.1080/03043797.2020.1781062.

Engineering Council. (2014). “Accreditation of Higher Education Programmes (AHEP)”.

Retrieved from https://www.engc.org.uk/standards-guidance/standards/accredita-

tion-of-higher-education-programmes-ahep/.

European Network for Accreditation of Engineering Education. "EUR-ACE Framework Standards for the Accreditation of Engineering Programmes.” 2008 Retrieved from https://www. enaee.eu/eur-ace-system/standards-and-guidelines/\#standards-and-guidelines-for-accreditation-of-engineering-programmes.

European Economic and Social Committee. "The role of engineers in the reindustrialization of Europe”. Brussels, EU: A. Pezzini, 2015. 
Ford, J.D., L. A. Riley. "Integrating communication and engineering education: a look at curricula, courses and support systems.” Journal of Engineering Education, 92, no. 4 .

Hofland, E., M. Pinxten, D. Wauters, G. Langie. “Roles” in the Bachelor's and Master's programmes in Engineering Technology.” Proceedings of the 43rd SEFI Annual Conference 2015 - Diversity in Engineering Education: An Opportunity to Face the New Trends of Engineering, 2015.

Idrus, H. "Developing Well-rounded Graduates through Integration of Soft Skills in the Teaching of Engineering Courses.” 2014 IEEE Frontiers in Education Conference (FIE) Proceedings. 1-9. Web, 2014.

Kamp, A., R. Klaassen. "Impact of Global Forces and Empowering Situations on Engineering Education in 2030.” In Proceedings of the 12th International CDIO Conference. Turku, Finland, 2019.

Kegan, R., \& Lahey, L. L.. "Immunity to change: How to overcome it and unlock potential in yourself and your organization.” Boston, MA: Harvard Business Press, 2009.

King, P. M., M. B. Baxter Magolda. "Student learning”. In J. H. Schuh, S. R. Jones \& S. R. Harper (Eds.), Student services: A handbook for the profession (pp. 207-225). San Francisco, CA: Jossey-Bass, 2011.

KU Leuven. Industrieel ingenieur 2020. "Bevraging van studenten, academic, professionals en werkveld.” Leuven, Belgium, 2015.

Liebenberg, L., E. Mathews. "Integrating Innovation Skills in an Introductory Engineering Design-build Course.” International Journal of Technology and Design Education 22, no. 1 (2012): 93-113. Web.

Male, S. A. "Generic Engineering Competencies: A Review and Modelling Approach.” Education Research and Perspectives, 37, no. 1, (2010): 25-51, 124. Web.

Male, S. A., M. B. Bush, E. S. Chapman. "Understanding Generic Engineering Competencies.” Australasian Journal of Engineering Education, 17, no. 3 (2011): 147-56.

MIT. (2018). "The global state of the art in engineering education”. Cambridge, USA: Graham, R. Mitchell, J. E., A. Nyamapfene, K. Roach, E. Tilley. "Faculty wide curriculum reform: the integrated engineering programme.” European Journal of Engineering Education, (2019): 1-19.

National Academy of Engineering. (2004). "The Engineer of 2020: Visions of Engineering in the New Century”. Washington, US.

National Academy of Engineering. "Engineering Societies and Undergraduate Engineering Education.” Washington, US: Steve Olson, 2017.

Nilsson, S. "Enhancing individual employability: the perspective of engineering graduates". Education + Training 52, no. 6/7, (2010): 540-551.

Royal Academy of Engineering. “Educating Engineers for the 21st Century.” London, UK, 2007. Royal Academy of Engineering. "Thinking like an engineer. Implications for the education system.” London, UK, 2014.

Royal Academy of Engineering. "Engineering skills for the future.” London, UK, 2019.

Spinks, N., N. L. J. Silburn, D. W. Birchall. "Making it all work: the engineering graduate of the future, a UK perspective.” European Journal of Engineering Education 32, no. 3, (2007): 325-335. https://doi.org/10.1080/03043790701278573.

Treacy, M., F. Wiersema. “Customer intimacy and other value disciplines.” Harvard Business Review 71, (1993): 84-93.

UNESCO Sustainable Development Goals. 2015. Retrieved from https://en.unesco.org/sdgs. 